\title{
Regioselective and stoichiometrically controlled conjugation of photodynamic sensitizers to a HER2 targeting antibody fragment.
}

Francesca Bryden†, Antoine Maruanił, Huguette Savoie†, Vijay Chudasamał, Mark E. B. Smithł, Stephen Caddick‡*, Ross W. Boyle†*.

†Department of Chemistry, University of Hull, Cottingham Road, Hull, HU6 7RX, UK.

$\ddagger$ Department of Chemistry, University College London, 20 Gordon Street, London, WC1H 0AJ, UK. 


\section{ABSTRACT}

The rapidly increasing interest in the synthesis of antibody-drug conjugates as powerful targeted anti-cancer agents demonstrates the growing appreciation of the power of antibodies and antibody fragments as highly selective targeting moieties. This targeting ability is of particular interest in the area of photodynamic therapy, as the applicability of current clinical photosensitizers is limited by their relatively poor accumulation in target tissue in comparison to healthy tissue. Although synthesis of porphyrin-antibody conjugates has been previously demonstrated, existing work in this area has been hindered by the limitations of conventional antibody conjugation methods. This work describes the attachment of azide-functionalised, water-soluble porphyrins to a tratuzumab Fab fragment via a novel conjugation methodology. This method allows for the synthesis of a homogenous product without the loss of structural stability associated with conventional methods of disulfide modification. Biological evaluation of the synthesised conjugates demonstrates excellent selectivity for a HER2 positive cell line over the control, with no dark toxicity observed in either case.

\section{INTRODUCTION}

The exploitation of the exquisite targeting ability of antibodies in combination with the cytotoxic action of anti-cancer agents is an area of growing popularity, with the recent approval of antibody-drug conjugates (ADCs) brentuximab vedotin (Adcetris ${ }^{\mathrm{TM}}$ ) and trastuzumab emtansine (Kadcyla ${ }^{\mathrm{TM}}$ ) reaffirming the clinical applicability of this targeting strategy. While all current clinical ADCs utilize a chemotherapeutic agent as the treatment modality, photodynamic therapy (PDT) offers an alternative method of cytotoxic action, operating via the action of a non-toxic photosensitizer which generates cytotoxic reactive oxygen species only when irradiated with light. Control of both photosensitizer localisation and light irradiation results in a "dual selectivity” of the photosensitizer, allowing effective tumour destruction while minimising damage to healthy tissue.

While we have previously demonstrated the highly effective therapeutic action of porphyrinantibody conjugates ${ }^{1-3}$ all earlier work in this area has been constrained by the limitations of currently available conjugation methods (see Boyle et al. for a comprehensive review ${ }^{4}$ ). Conjugation to antibodies is typically achieved through either multiple lysine modification or by functionalization of thiols generated by reduction of interchain disulfide bonds, however neither of these conjugation strategies is ideal. ${ }^{5} 6$ Lysine modification generates heterogeneous products, 
which in the context of ADCs have been shown to have a narrow therapeutic window relative to homogeneous variants. ${ }^{7,8}$ With respect to disulfide modification, while conventional methods of cysteine modification following interchain disulfide reduction avoid this issue, ${ }^{1}$ they also result in the permanent loss of structural disulfide bonds, which may reduce the stability of the antibody in vivo. ${ }^{5,6}$

An elegant alternative is the recently described method for the insertion of dibromomaleimides into disulfide bonds in various proteins, engineered antibody single-chain variable fragments (scFv) and a fragment antigen-binding (Fab) constructs, which allows the synthesis of homogeneous products with retention of a rigid structural bridge. ${ }^{9-14}$ It was envisaged that this disulfide modification technology could be combined with our current interest in mild bioorthogonal conjugation of porphyrin photosensitizers to targeting moieties, ${ }^{15-17}$ in particular through use of the Copper-Catalysed Azide-Alkyne Cycloaddition (CuAAC) reaction. This reaction is mild and generally high yielding ${ }^{18,19}$ and has been shown to be highly compatible with porphyrin bioconjugation, being largely insensitive to steric hindrance and operating well in aqueous conditions without the need for high temperatures or long reaction times. It was therefore rationalised that the combination of these two strategies could be utilised to deliver a bioconjugation methodology which is mild, facile and highly selective, providing an attractive route towards the generation of antibody-targeted PDT agents.

Trastuzumab $\left(\right.$ Herceptin $^{\mathrm{TM}}$ ) is an internalising monoclonal IgG1 antibody that targets the HER2 receptor, an epidermal growth factor receptor which is over-expressed in around $25-30 \%$ of all cases of breast cancer and has been shown to be associated with poor prognosis, metastasis and cancer recurrence. ${ }^{20}$ The Fab fragment of trastuzumab was selected as it is an appealing antibody fragment system on which to evaluate our PDT strategy for a number of reasons: (i) unlike monoclonal antibodies, Fab fragments can be expressed in bacteria; (ii) they demonstrate good cell penetration; (iii) Fabs bearing an agent capable of cytotoxic action do not require antibodydependent cellular cytotoxicity (ADCC) to have a therapeutic effect; and (iv) trastuzumab has been used successfully in the treatment of HER2-positive breast cancer ${ }^{21}$ and is also the antibody component of FDA-approved breast cancer ADC trastuzumab emtansine. ${ }^{22}$ In addition, the heavy and light chains of Fab fragments are connected via a single interchain disulfide bond, on which re-bridging with dibromomaleimides has previously been demonstrated to have minimal impact on receptor binding. ${ }^{9}$

As a result, it was envisaged that functional bridging of this interchain disulfide with $N$-propargyl-3,4-dibromomaleimide 3 would yield a homogeneous product that could be readily 
functionalised with one of two azide-bearing water-soluble porphyrins, 1 and 2 (Figure 1), to produce antibody-targeted photosensitizers suitable for biological evaluation.

\section{EXPERIMENTAL}

\section{Synthesis}

All reactions were monitored by thin-layer chromatography (TLC) on pre-coated SIL G/UV254 silica gel plates $(254 \mu \mathrm{m}) .{ }^{1} \mathrm{H}$ and ${ }^{13} \mathrm{C}$ NMR spectra were recorded at ambient temperature on a Bruker Avance 600 instrument and a Jeol JNMLA400 spectrometer. The chemical shifts $(\delta)$ for ${ }^{1} \mathrm{H}$ and ${ }^{13} \mathrm{C}$ are quoted relative to residual signals of the solvent on the ppm scale. Coupling constants ( $J$ values) are reported in Hertz $(\mathrm{Hz})$ and are $\mathrm{H}-\mathrm{H}$ coupling constants unless otherwise stated. Signal multiplicities in ${ }^{13} \mathrm{C}$ NMR were determined using the distortionless enhancement by phase transfer (DEPT) spectral editing technique. Infrared spectra were obtained on a Perkin Elmer Spectrum 100 FTIR Spectrometer operating in ATR mode with frequencies given in reciprocal centimetres $\left(\mathrm{cm}^{-1}\right)$. UV-Vis spectra were measured on a Varian Cary 50 Bio UV-Vis spectrophotometer. Melting points were measured with a Gallenkamp apparatus and are uncorrected. Mass spectra of $\mathbf{1}$ and $\mathbf{2}$ and their precursors were obtained from the EPSRC National Mass Spectrometry Service, Swansea, all other mass spectrometry data was collected on a VG70-SE mass spectrometer. Porphyrins $\mathbf{1}$ and $\mathbf{2}$ were prepared according to the method of Giuntini et al. ${ }^{23}$ Synthesis of $\mathbf{3}$ was carried out according to the method of Castañeda et al. ${ }^{24}$

\section{Fab fragment preparation}

LC-MS was performed on protein samples using a Thermo Scientific uPLC connected to MSQ Plus Single Quad Detector (SQD). Column: Hypersil Gold C4, 1.9 m 2.1 × 50 mm. Wavelength: $254 \mathrm{~nm}$. Mobile Phase: 99:1 Water:MeCN (0.1\% formic acid) to 1:9 Water: MeCN (0.1\% formic acid) gradient over 4 min. Flow Rate: $0.3 \mathrm{~mL} / \mathrm{min}$. MS Mode: $\mathrm{ES}^{+}$. Scan Range: $\mathrm{m} / \mathrm{z}=500-2000$. Scan time: $1.5 \mathrm{~s}$. Data obtained in continuum mode. The electrospray source of the MS was operated with a capillary voltage of $3.5 \mathrm{kV}$ and a cone voltage of $50 \mathrm{~V}$. Nitrogen was used as the nebulizer and desolvation gas at a total flow of $600 \mathrm{~L} / \mathrm{h}$. Ion series were generated by integration of the total ion chromatogram (TIC) over the 3.5-5.0 min range. Total mass spectra for protein samples were reconstructed from the ion series using the pre-installed ProMass software. 
Trastuzumab Fab 4. Immobilized pepsin $(0.15 \mathrm{~mL})$ was washed with digestion buffer $(20 \mathrm{mM}$ sodium acetate trihydrate, $\mathrm{pH} 3.1)$ four times and trastuzumab $(0.5 \mathrm{~mL}, 6.41 \mathrm{mg} / \mathrm{mL}$ in digestion buffer) was added. The mixture was incubated for $5 \mathrm{~h}$ at $37^{\circ} \mathrm{C}$ whilst shaking (1100 rpm). The resin was separated from the digest using a filter column, and washed with digest buffer (50 mM phosphate, $1 \mathrm{mM}$ EDTA, $150 \mathrm{mM} \mathrm{NaCl}, \mathrm{pH}$ 6.8) three times. The digest was combined with the washes and the volume adjusted to $0.5 \mathrm{~mL}$. The sample was analysed by LCMS, which revealed formation of trastuzumab-F(ab')2, LCMS observed mass: 97303. After this, immobilized papain (0.5 mL, $0.25 \mathrm{mg} / \mathrm{mL}$ ) was activated with $10 \mathrm{mM}$ DTT (in digest buffer: $50 \mathrm{mM}$ phosphate, 1 mM EDTA, $150 \mathrm{mM} \mathrm{NaCl}$, pH 6.8) whilst shaking (1100 rpm) for $1 \mathrm{~h}$ at $37^{\circ} \mathrm{C}$. The resin was washed with digest buffer (without DTT) four times and the $0.5 \mathrm{~mL}$ of Herceptin-F(ab’) 2 added. The mixture was incubated for $16 \mathrm{~h}$ at $37^{\circ} \mathrm{C}$ whilst shaking (1100 rpm). Then the resin was separated from the digest using a filter column, and washed with BBS (25 mM sodium borate, 25 $\mathrm{mM} \mathrm{NaCl}, 0.5 \mathrm{mM}$ EDTA, pH 8.0) three times. The digest was combined with the washes and the buffer was exchanged completely for BBS using diafiltration columns (GE Healthcare, 10,000 MWCO) and the volume adjusted to $0.5 \mathrm{~mL}$. The digest was analysed by SDS-PAGE and LCMS to reveal formation of a single trastuzumab Fab fragment: observed monoisotopic mass 47651. The concentration of trastuzumab Fab fragment was determined by UV/VIS using a molecular extinction coefficient of $\varepsilon_{280}=68590 \mathrm{M}^{-1} \mathrm{~cm}^{-1}$. [trastuzumab Fab fragment] $2.8 \mathrm{mg} / \mathrm{mL}$ (0.5 mL), 67\%.

\section{Fab-porphyrin bioconjugation}

Reduced trastuzumab Fab 5. To a solution of Fab fragment $4(50 \mu \mathrm{L}, 36 \mu \mathrm{M}, 1.72 \mathrm{mg} / \mathrm{mL}$ in 25 mM sodium borate, $25 \mathrm{mM} \mathrm{NaCl}, 0.5 \mathrm{mM}$ EDTA, pH 8.0) was added TCEP ( $5 \mu \mathrm{L}, 0.12 \mathrm{mM}$ ) to affect reduction of the interchain disulfide. After $1.5 \mathrm{~h}$ at $37^{\circ} \mathrm{C}$, the excess TCEP was removed by ultrafiltration (GE Healthcare, 10,000 MWCO) into fresh buffer ( $25 \mathrm{mM}$ sodium borate, 25 $\mathrm{mM} \mathrm{NaCl}, 0.5 \mathrm{mM}$ EDTA, $\mathrm{pH}$ 8.0) and the reaction mixture analysed by LCMS to reveal the heavy and light chains only (i.e. reduced trastuzumab Fab fragment).

Trastuzumab Fab-alkyne 6. To a solution of reduced trastuzumab Fab fragment 5 ( $21 \mu \mathrm{M}, 1$ $\mathrm{mg} / \mathrm{mL}$ in $25 \mathrm{mM}$ sodium borate, $25 \mathrm{mM} \mathrm{NaCl}, 0.5 \mathrm{mM}$ EDTA, pH 8.0) was added $N$-propargyl3,4-dibromomaleimide ( $50 \mu \mathrm{L}$ per $\mathrm{mL}$ of Fab, $2.2 \mathrm{mM}$ solution in DMF) to affect re-bridging of the interchain disulfide. After $1 \mathrm{~h}$ at $37^{\circ} \mathrm{C}$, the reaction was complete and the excess $N$-propargyl-3,4-dibromomaleimide 3 removed by repeated ultrafiltration (GE Healthcare, 10,000 MWCO) into fresh buffer (PBS, pH 7.4). Analysis by LCMS and SDS-PAGE revealed re-bridged 
trastuzumab Fab-alkyne 6: observed monoisotopic mass 47785, expected monoisotopic mass 47784.

General procedure for Copper(I)-catalysed Azide-Alkyne Cycloaddition (CuAAC). To a solution of trastuzumab Fab-alkyne $6(50 \mu \mathrm{L}, 42 \mu \mathrm{M}, 2 \mathrm{mg} / \mathrm{mL})$ in PBS (pH 7.4) containing tris(3-hydroxypropyltriazolylmethyl)amine (THPTA) $(500 \mu \mathrm{M}), \mathrm{CuSO}_{4}(100 \mu \mathrm{M})$ and aminoguanidine $\cdot \mathrm{HCl}(5 \mathrm{mM}$ ) was added azide porphyrin (final concentration $130 \mu \mathrm{M}, 3 \mathrm{eq}$ ) and sodium ascorbate (final concentration $5 \mathrm{mM}$ ) and the reaction mixture incubated at $25^{\circ} \mathrm{C}$ for $1 \mathrm{~h}$. The excess reagents were removed by repeated ultrafiltration (GE Healthcare, 10,000 MWCO) into fresh buffer (PBS, pH 7.4). Analysis by LCMS and SDS-PAGE was then performed.

Synthesis of trastuzumab Fab porphyrin 7. Using the general procedure for Copper(I)catalysed Azide-Alkyne Cycloaddition (CuAAC) for azide porphyrin 1, analysis by LCMS and SDS-PAGE revealed trastuzumab Fab porphyrin 7: observed monoisotopic mass of trastuzumab Fab porphyrin 7 48555, expected monoisotopic mass 48552.

Synthesis of trastuzumab Fab PEG-porphyrin 8. Using the general procedure for Copper(I)catalysed Azide-Alkyne Cycloaddition (CuAAC) for azide PEG-porphyrin 2, analysis by LCMS and SDS-PAGE revealed trastuzumab Fab porphyrin 8: observed monoisotopic mass of trastuzumab Fab porphyrin 8 48712, expected monoisotopic mass 48711.

\section{Cell culture}

Human breast carcinoma cell lines BT-474 (HER2 positive) and MDA-MB-468 (HER2 negative) were respectively grown in Hybricare medium (ATCC, 46-X) + 10\% FCS (Bio-Sera, S1810) and in MEM High glucose (Gibco-Life Technologies A-14518-01) + 10\% FCS (Bio-Sera, S1810) and $2 \mathrm{mM}$ L-glutamine (Gibco- Life Technologies 25030), at a constant $37^{\circ} \mathrm{C}$ and $5 \% \mathrm{CO}_{2}$.

\section{Cytotoxicity methodology}

Each conjugate was diluted in the appropriate medium, but without FCS, to give a range of five concentrations varying between $1 \times 10^{-5} \mathrm{M}$ and $1 \times 10^{-7} \mathrm{M} .400 \mu \mathrm{L}$ of each cell line adjusted to a concentration of $1 \times 10^{6}$ cells/mL was added to the dilutions and incubated for $1 \mathrm{~h}$ at $37^{\circ} \mathrm{C}$ and $5 \% \mathrm{CO}_{2}$. After incubation the cells were washed with a $4 \times$ excess of serum free medium to eliminate any unbound conjugate. The pellets were re-suspended in $0.5 \mathrm{~mL}$ of the appropriate serum free medium and $100 \mu \mathrm{L}$ aliquoted into 5 wells of a 96-well plate. Each plate was irradiated with $20 \mathrm{~J} / \mathrm{cm}^{2}$ of light (400 - $700 \mathrm{~nm}$ ) in two equal doses separated by 10 min delivered using an Oriel, 1000W quartz tungsten halogen lamp fitted with water filter and diffuser. After 
irradiation, $5 \mu \mathrm{L}$ of fetal bovine serum was added to each well and the plates were returned to the incubator overnight. After 24 h, an MTT (Thiazolyl blue; Sigma M5655) cell viability assay was performed and the results expressed as \% of cell viability versus porphyrin-conjugate concentration.

\section{RESULTS AND DISCUSSION Synthesis and characterisation}

Two porphyrins were selected for investigation, one functionalised directly with the azido group required for conjugation, $\mathbf{1}$, and the second bearing a short polyethylene glycol (PEG) spacer chain, 2. Our reasoning for this was based on a previous study ${ }^{1}$ in which direct conjugation of porphyrins to the thiol groups of cysteine residues on the small immune protein format of the L19 (SIP-L19) antibody resulted in reduced activity, presumably due to excited state quenching caused by the close proximity of porphyrin and SIP-L19.

Synthesis of both porphyrins was carried out according to a previously published method ${ }^{23}$ with azide functionalization of the precursor porphyrins accomplished through diazotization of an aryl amine and peptide coupling to a commercially available azide PEG chain respectively. Methylation followed by zinc complexation of the free-base porphyrin was carried out to yield the water-soluble, azide-bearing porphyrins in excellent yields, with both products fully characterised by NMR and MS. Synthesis of the heterobifunctional linker $\mathbf{3}$ was also carried out according to a previously developed method ${ }^{24}$ with the initial synthesis of an activated $\mathrm{N}$-methoxycarbonyl derivative followed by reaction with propargylamine to generate the desired product in $80 \%$ overall yield, with the identity of the product confirmed by NMR, MS and IR.

\section{Bioconjugation}

To access trastuzumab-Fab $\mathbf{4}$ an optimised version of a previously reported protocol was applied. It involved sequential digests of trastuzumab with pepsin, to yield a $\mathrm{F}\left(\mathrm{ab}{ }^{\prime}\right)_{2}$ fragment, and papain to afford the desired Fab fragment as a single product in good yield (Scheme 1). ${ }^{9}$ TrastuzumabFab 4 was treated with tris(2-carboxyethyl)-phosphine (TCEP) in order to reduce the interchain disulfide bridge, with the two fragments clearly visible on MS following cleavage of the disulfide bridge (Figure 2). Subsequent treatment with $N$-propargyl-3,4-dibromomaleimide 3 yielded bioconjugate $\mathbf{6}$ in near quantitative yield, with the complete consumption of $\mathbf{4}$ confirmed by MS. Trastuzumab-Fab alkyne $\mathbf{6}$ was then successfully reacted with porphyrins $\mathbf{1}$ and $\mathbf{2}$ to afford Fabporphyrins 7 and $\mathbf{8}$ respectively, and the products characterised by SDS-PAGE and mass 
spectrometry (Figure 3). Interestingly, no significant difference in the reactivity of porphyrins 1 and $\mathbf{2}$ was observed despite the increased steric hindrance expected in relation to porphyrin $\mathbf{1}$. This suggests that this conjugation methodology would be suitable for conjugation of other bulky azide-functionalised compounds. This methodology could also be applied without the need for a catalyst through the use of the strain-promoted azide-alkyne cycloaddition (SPAAC) reaction as an alternative to the CuAAC reaction, with functionalization of the antibody fragment with a strained alkyne structure allowing mild and bioorthogonal attachment without the need for copper catalysis. Use of the SPAAC methodology has previously been demonstrated as an antibodyfunctionalisation tool by Zimmerman et $a l^{25}$, and is ideally suited for use with copper-sensitive substrates or in the development of in vivo bioconjugation methodologies.

The results described suggest that the conjugation methods developed offer a convenient approach to the assembly of antibody-targeted conjugates for use in photodynamic therapy. The water-soluble, cationic $\mathrm{A}_{3} \mathrm{~B}$-type porphyrins selected for conjugation to the trastuzumab-Fab used in this study have previously been shown to be highly efficient photodynamic agents, both in $v$ itro ${ }^{1}$ and in vivo ${ }^{2}$. Interestingly, in the latter case these porphyrins were also shown to provoke a strong anti-tumour immune response, which offers exciting possibilities for suppression of small metastatic tumour, in addition to eradication of the primary mass. Although porphyrins were selected in this study due to their proven efficacy, it is anticipated that the methodology can easily be adapted to other photoactive molecules or macrocycles with similar physicochemical features i.e. water solubility and azide functionality, therefore making this a possible platform technology suitable for labelling antibody fragments with optical- or radio-imaging agents.

\section{Cellular studies}

In order to determine the potential of the conjugates to differentiate between HER2 positive and HER2 negative cells, and assess their photodynamic effects, experiments were carried out as described in the experimental section. In these experiments, broad spectrum light was used to ensure sufficient activation of the photosensitizer from the QTH lamp used. Clinically, light in the red region of the spectrum would more typically be used, where the weaker absorption of the porphyrins in this region is compensated for by using biomedical lasers with light fluences which are orders of magnitude greater than those used here. The present study was thus designed to assess photodynamic potential in vitro and further studies using red light would clearly be needed before moving to a clinical setting.

Under these conditions it can unambiguously be seen that both conjugates exhibit remarkable abilities to eradicate HER2 positive cells (ca. 90\% kill), while at the same concentration leaving 
HER2 negative cells unaffected (Figure 4). In both cell lines, both conjugates 7 and $\mathbf{8}$ displayed no dark toxicity, with photosensitizer at the highest concentration showing no cell death in the absence of irradiating light. Although based previous work ${ }^{1}$ it was expected that the close proximity of the porphyrin and antibody fragment in conjugate $\mathbf{7}$ would lead to excited state quenching and therefore poorer singlet oxygen quantum yield, no significant difference in the cytotoxicity of conjugates $\mathbf{7}$ and $\mathbf{8}$ was observed. The reason for this unexpected result is unknown, however it is hypothesised that the dibromomaleimides conjugation methodology offers two distinct advantages over the maleimide conjugation demonstrated by Alonso et al, allowing conjugation of porphyrins without the need for a PEG spacer group.

Firstly, the dibromomaleimide allows for functional rebridging of the disulfide bridge, maintaining structural integrity of the antibody. This is unlike the maleimide group, which does not bridge the antibody, and therefore the structure of the antibody fragment must be maintained by hydrophobic interactions only. Rebridging the disulfide bridge in this way maintains the fixed distance between the two sections of the Fab fragment, allowing sufficient space for a porphyrin to be conjugated between these two sections without quenching due to the close proximity of the porphyrin to the antibody fragment. Secondly, use of the dibromomaleimide functionality allows conjugation of a single porphyrin per disulfide bridge rather than the 2:1 ratio obtained through use of maleimide. Reducing the loading ratio of porphyrins in this way prevents interactions between two porphyrins in close proximity, therefore removing any quenching of the porphyrin from this effect.

\section{CONCLUSION}

In conclusion, we have demonstrated a novel bioconjugation methodology allowing the mild and facile conjugation of azide-functionalised porphyrins to an alkyne bearing maleimide inserted into the disulfide bridge of an antibody fragment in a homogenous and site-specific manner. Subsequent evaluation of the therapeutic effects of two porphyrin-antibody conjugates in vitro demonstrated excellent selectivity for a HER2 positive cell line over the control, with no dark toxicity observed in both cell lines.

\section{AUTHOR INFORMATION}

Corresponding authors: 
*Department of Chemistry, The University of Hull, Cottingham Road, Hull, HU6 7RX, UK. Email: r.w.boyle@hull.ac.uk, Telephone: +44 (0)1482 466353 Fax: +44 (0)1482 466410.

*Department of Chemistry, University College London, 20 Gordon Street, London, WC1H 0AJ, UK. Email: VPEnterprise@ucl.ac.uk, Telephone: +44 (0)20 31087538.

\section{ACKNOWLEDGEMENTS}

Mass spectrometry data was acquired at the EPSRC UK National Mass Spectrometry Facility at Swansea University.

\section{SUPPORTING INFORMATION AVAILABLE}

NMR data for all compounds and precursors, SDS-PAGE and MS data for conjugates 3-7. This material is available free of charge via the Internet at http://pubs.acs.org.

\section{ABBREVIATIONS}

ADC, antibody-drug conjugate; ADCC, antibody-dependent cellular cytotoxicity; CuAAC, copper-catalyzed azide-alkyne cycloaddition; Fab, fragment antigen-binding; HER2, human epidermal growth factor receptor 2, PDT, photodynamic therapy; PEG, polyethylene glycol; ScFv, single-chain variable fragments; TCEP, tris(2-carboxyethyl)-phosphine; THPTA, tris(3hydroxypropyltriazolylmethyl)amine.

\section{REFERENCES}

(1) Alonso, C. M. A., Palumbo, A., Bullous, A. J., Pretto, F., Neri, D., and Boyle, R. W. (2010) SiteSpecific and Stoichiometric Conjugation of Cationic Porphyrins to Antiangiogenic Monoclonal Antibodies. Bioconjugate Chem 21, 302-313.

(2) Sengupta, S., Uemura, S., Patwardhan, S., Huber, V., Grozema, F. C., Siebbeles, L. D. A., Baumeister, U., and Würthner, F. (2011) Columnar Mesophases Based on Zinc Chlorophyll Derivatives Functionalized with Peripheral Dendron Wedges. Chem-Eur J 17, 5300-5310.

(3) Hudson, R., Carcenac, M., Smith, K., Madden, L., Clarke, O. J., Pelegrin, A., Greenman, J., and Boyle, R. W. (2005) The development and characterisation of porphyrin isothiocyanatemonoclonal antibody conjugates for photoimmunotherapy. Brit J Cancer 92, 1442-1449.

(4) Bullous, A. J., Alonso, C. M. A., and Boyle, R. W. (2011) Photosensitiser-antibody conjugates for photodynamic therapy. Photochem Photobiol Sci 10, 721-750.

(5) Flygare, J. A., Pillow, T. H., and Aristoff, P. (2013) Antibody-Drug Conjugates for the Treatment of Cancer. Chemical Biology \& Drug Design 81, 113-121.

(6) Ducry, L., and Stump, B. (2009) Antibody-Drug Conjugates: Linking Cytotoxic Payloads to Monoclonal Antibodies. Bioconjugate Chem 21, 5-13.

(7) Junutula, J. R., Flagella, K. M., Graham, R. A., Parsons, K. L., Ha, E., Raab, H., Bhakta, S., Nguyen, T., Dugger, D. L., Li, G., Mai, E., Lewis Phillips, G. D., Hiraragi, H., Fuji, R. N., Tibbitts, 
J., Vandlen, R., Spencer, S. D., Scheller, R. H., Polakis, P., and Sliwkowski, M. X. (2010)

Engineered Thio-Trastuzumab-DM1 Conjugate with an Improved Therapeutic Index to Target Human Epidermal Growth Factor Receptor 2-Positive Breast Cancer. Clin Cancer Res 16, 4769-4778.

(8) Junutula, J. R., Raab, H., Clark, S., Bhakta, S., Leipold, D. D., Weir, S., Chen, Y., Simpson, M., Tsai, S. P., Dennis, M. S., Lu, Y., Meng, Y. G., Ng, C., Yang, J., Lee, C. C., Duenas, E., Gorrell, J., Katta, V., Kim, A., McDorman, K., Flagella, K., Venook, R., Ross, S., Spencer, S. D., Lee Wong, W., Lowman, H. B., Vandlen, R., Sliwkowski, M. X., Scheller, R. H., Polakis, P., and Mallet, W. (2008) Site-specific conjugation of a cytotoxic drug to an antibody improves the therapeutic index. Nat Biotech 26, 925-932.

(9) Schumacher, F. F., Nobles, M., Ryan, C. P., Smith, M. E. B., Tinker, A., Caddick, S., and Baker, J. R. (2011) In Situ Maleimide Bridging of Disulfides and a New Approach to Protein PEGylation. Bioconjugate Chem 22, 132-136.

(10) Schumacher, F. F., Sanchania, V. A., Tolner, B., Wright, Z. V. F., Ryan, C. P., Smith, M. E. B., Ward, J. M., Caddick, S., Kay, C. W. M., Aeppli, G., Chester, K. A., and Baker, J. R. (2013) Homogeneous antibody fragment conjugation by disulfide bridging introduces /'spinostics/'. Sci. Rep. 3.

(11) Ryan, C. P., Smith, M. E. B., Schumacher, F. F., Grohmann, D., Papaioannou, D., Waksman, G., Werner, F., Baker, J. R., and Caddick, S. (2011) Tunable reagents for multi-functional bioconjugation: reversible or permanent chemical modification of proteins and peptides by control of maleimide hydrolysis. Chem Commun 47, 5452-5454.

(12) Smith, M. E. B., Schumacher, F. F., Ryan, C. P., Tedaldi, L. M., Papaioannou, D., Waksman, G., Caddick, S., and Baker, J. R. (2010) Protein Modification, Bioconjugation, and Disulfide Bridging Using Bromomaleimides. J Am Chem Soc 132, 1960-1965.

(13) Castaneda, L., Maruani, A., Schumacher, F. F., Miranda, E., Chudasama, V., Chester, K. A., Baker, J. R., Smith, M. E. B., and Caddick, S. (2013) Acid-cleavable thiomaleamic acid linker for homogeneous antibody-drug conjugation. Chem Commun 49, 8187-8189.

(14) Chudasama, V., Smith, M. E. B., Schumacher, F. F., Papaioannou, D., Waksman, G., Baker, J. R., and Caddick, S. (2011) Bromopyridazinedione-mediated protein and peptide bioconjugation. Chem Commun 47, 8781-8783.

(15) Giuntini, F., Bryden, F., Daly, R., Scanlan, E. M., and Boyle, R. W. (2014) Huisgen-based conjugation of water-soluble porphyrins to deprotected sugars: towards mild strategies for the labelling of glycans. Org Biomol Chem 12, 1203-1206.

(16) Giuntini, F., Dumoulin, F., Daly, R., Ahsen, V., Scanlan, E. M., Lavado, A. S. P., Aylott, J. W., Rosser, G. A., Beeby, A., and Boyle, R. W. (2012) Orthogonally bifunctionalised polyacrylamide nanoparticles: a support for the assembly of multifunctional nanodevices. Nanoscale 4, 2034-2045.

(17) Bryden, F., and Boyle, R. W. (2013) A Mild, Facile, One-Pot Synthesis of Zinc Azido Porphyrins as Substrates for Use in Click Chemistry. Synlett 24, 1978-1982.

(18) Rostovtsev, V. V., Green, L. G., Fokin, V. V., and Sharpless, K. B. (2002) A Stepwise Huisgen Cycloaddition Process: Copper(I)-Catalyzed Regioselective "Ligation" of Azides and Terminal Alkynes. Angew. Chem., Int. Ed. 41, 2596-2599.

(19) Fathalla, M., Li, S.-C., Diebold, U., Alb, A., and Jayawickramarajah, J. (2009) Water-soluble nanorods self-assembled via pristine $\mathrm{C} 60$ and porphyrin moieties. Chem Commun 0, 42094211.

(20) Cobleigh, M. A., Vogel, C. L., Tripathy, D., Robert, N. J., Scholl, S., Fehrenbacher, L., Wolter, J. M., Paton, V., Shak, S., Lieberman, G., and Slamon, D. J. (1999) Multinational Study of the Efficacy and Safety of Humanized Anti-HER2 Monoclonal Antibody in Women Who Have HER2-Overexpressing Metastatic Breast Cancer That Has Progressed After Chemotherapy for Metastatic Disease. Journal of Clinical Oncology 17, 2639. 
(21) Hudis, C. A. (2007) Drug therapy: Trastuzumab - Mechanism of action and use in clinical practice. New England Journal of Medicine 357, 39-51.

(22) Verma, S., Miles, D., Gianni, L., Krop, I. E., Welslau, M., Baselga, J., Pegram, M., Oh, D.-Y., Diéras, V., Guardino, E., Fang, L., Lu, M. W., Olsen, S., and Blackwell, K. (2012) Trastuzumab Emtansine for HER2-Positive Advanced Breast Cancer. New England Journal of Medicine 367, 1783-1791.

(23) Giuntini, F., Bryden, F., Daly, R., Scanlan, E. M., and Boyle, R. W. (2014) Huisgen-based conjugation of water-soluble porphyrins to deprotected sugars: towards mild strategies for the labelling of glycans. Org Biomol Chem.

(24) Castañeda, L., Wright, Z. V. F., Marculescu, C., Tran, T. M., Chudasama, V., Maruani, A., Hull, E. A., Nunes, J. P. M., Fitzmaurice, R. J., Smith, M. E. B., Jones, L. H., Caddick, S., and Baker, J. R. (2013) A mild synthesis of $\mathrm{N}$-functionalised bromomaleimides, thiomaleimides and bromopyridazinediones. Tetrahedron Lett 54, 3493-3495.

(25) Zimmerman, E. S., Heibeck, T. H., Gill, A., Li, X., Murray, C. J., Madlansacay, M. R., Tran, C., Uter, N. T., Yin, G., Rivers, P. J., Yam, A. Y., Wang, W. D., Steiner, A. R., Bajad, S. U., Penta, K., Yang, W., Hallam, T. J., Thanos, C. D., and Sato, A. K. (2014) Production of Site-Specific Antibody-Drug Conjugates Using Optimized Non-Natural Amino Acids in a Cell-Free Expression System. Bioconjugate Chem., DOI: 10.1021/bc400490z.

\section{Schemes and Charts}

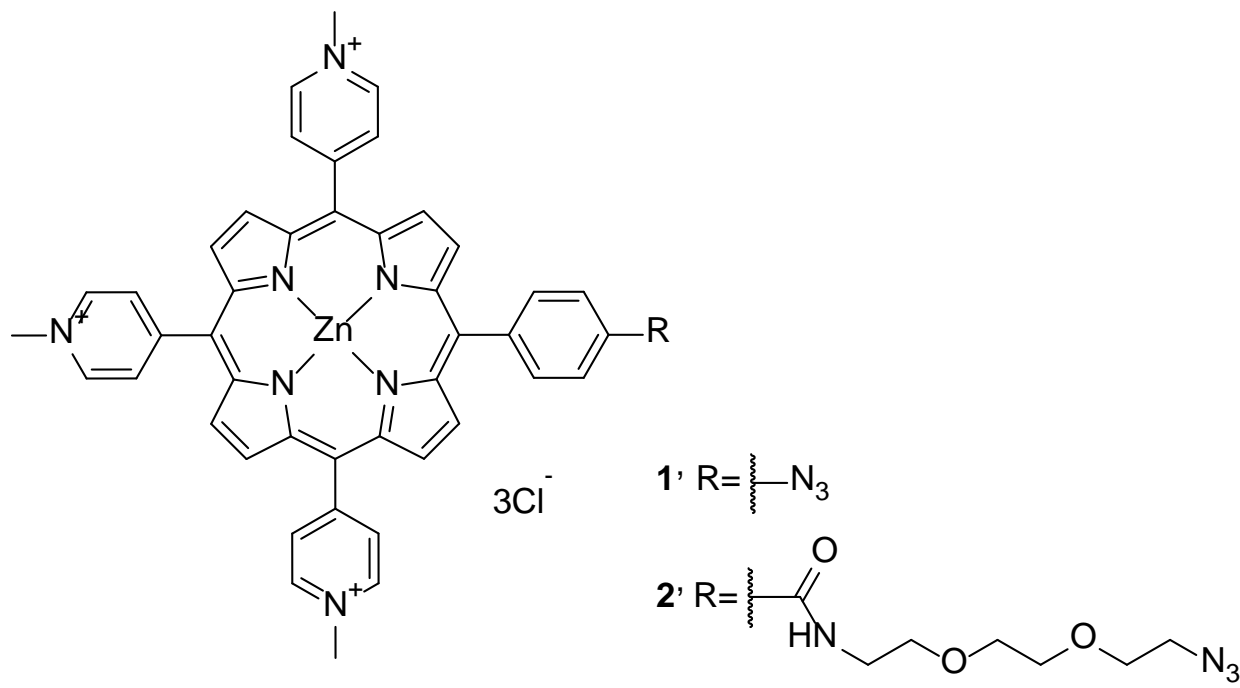

Figure 1: Structures of water-soluble, conjugatable porphyrins 1 and 2. 

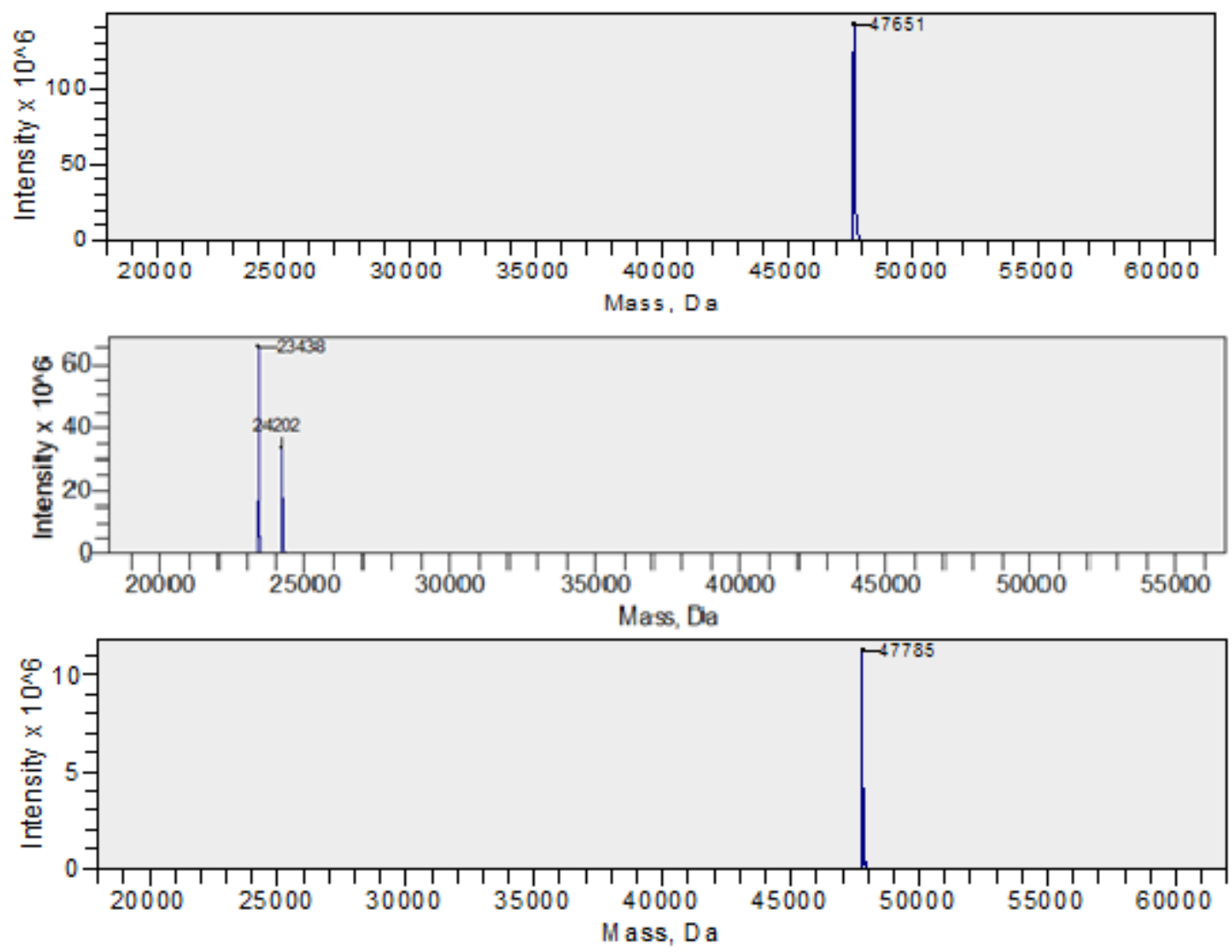

Figure 2: Deconvoluted MS data for Fab fragment 4 (top), reduced Fab fragment 5 (middle) and alkyne bridged Fab fragment 6 (bottom).
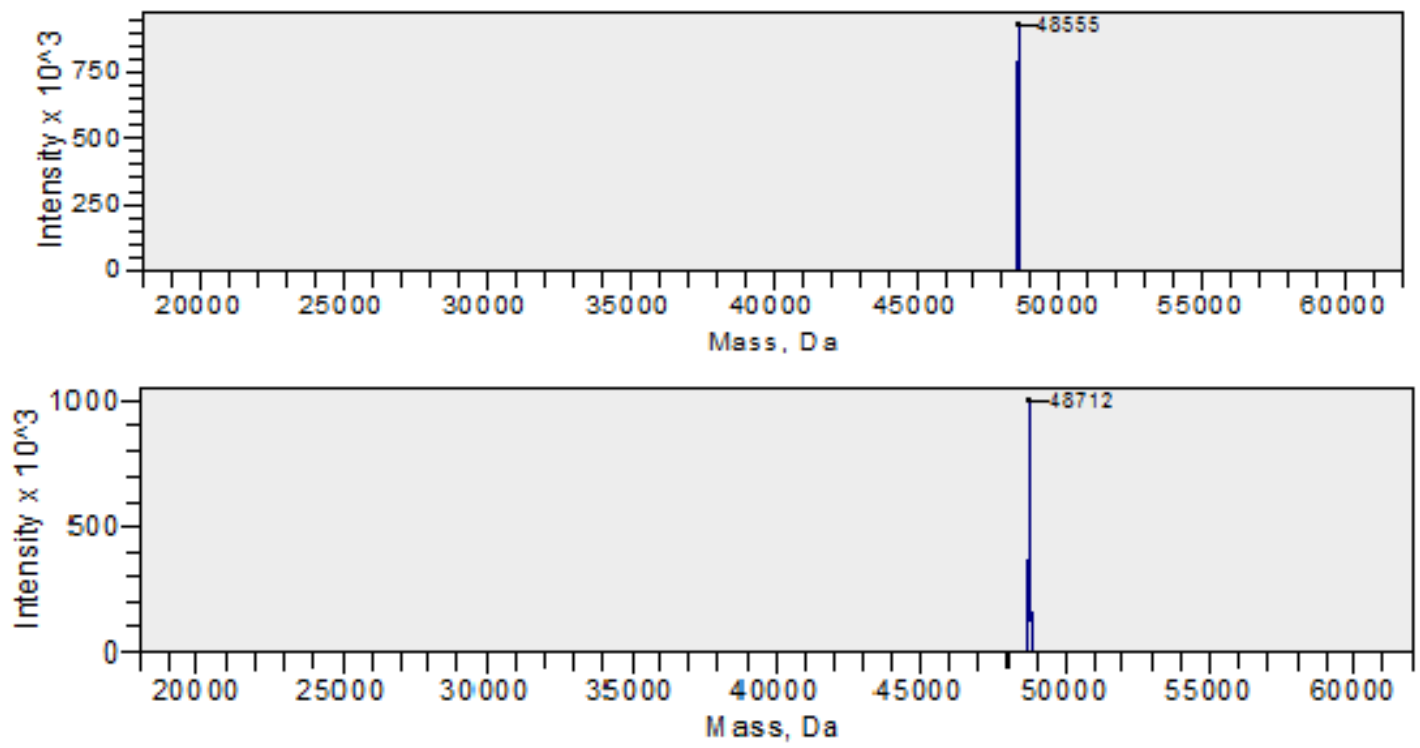

Figure 3: Deconvoluted MS data for porphyrin-Fab fragment conjugates 7 (top) and 8 (bottom). 


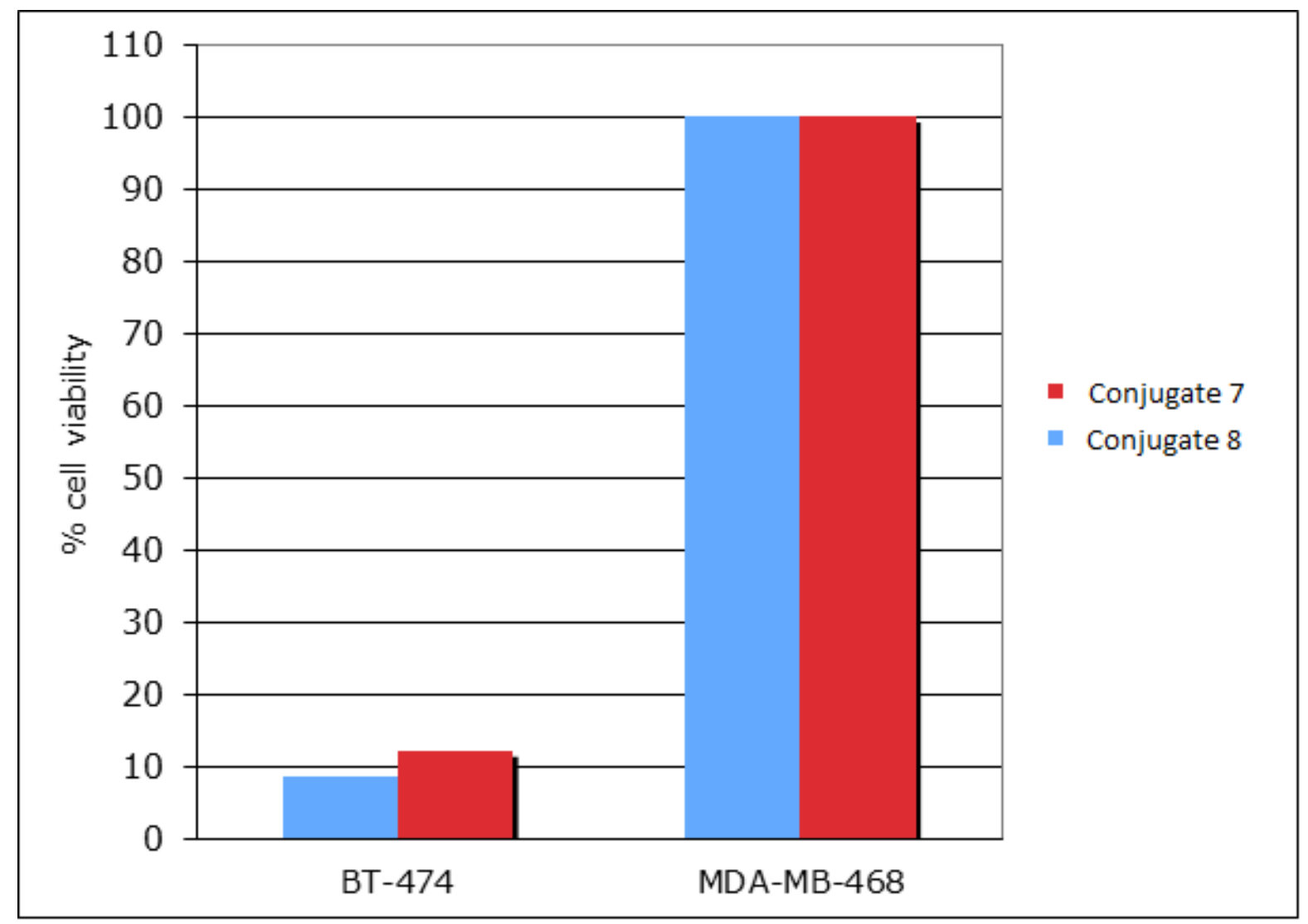

Figure 4: Percentage cell viability for HER2 positive cells (BT-474) and HER2 negative cells (MDA-MB-468) determined by MTT assay $24 \mathrm{~h}$ after incubation with $1 \mu \mathrm{M}$ of conjugates 7 and 8 and irradiation with $20 \mathrm{~J} / \mathrm{cm}^{2}$ light $(400-700 \mathrm{~nm})$. 


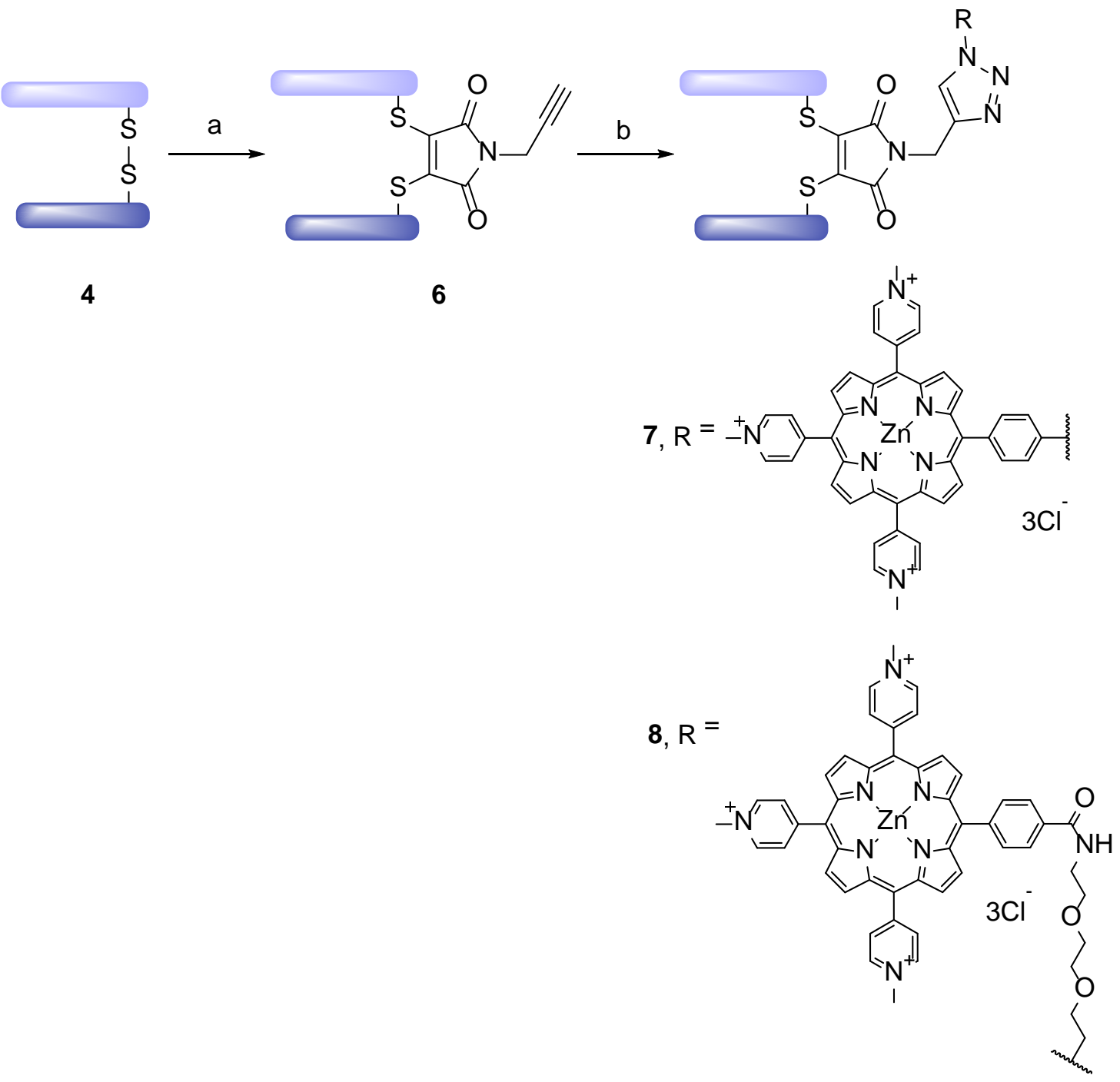

Scheme 1. Conversion of trastuzumab-Fab 4 to Fab-porphyrins 7 and 8; conditions: (a) TCEP, pH 8.0, $37^{\circ} \mathrm{C}, 1.5 \mathrm{~h}$, then $N$-propargyl-3,4-dibromomaleimide, $37^{\circ} \mathrm{C}, 1 \mathrm{~h}$; (b) azide porphyrin 1 or 2, THPTA, $\mathrm{CuSO}_{4}$, aminoguanidine· $\mathrm{HCl}$, sodium ascorbate, $\mathrm{PBS}, \mathrm{pH} 7.4,25^{\circ} \mathrm{C}, 1 \mathrm{~h}$. 